\title{
LAS FORMAS NEXUALES ADVERSATIVAS EN EL HABLA CULTA COSTARRICENSE
}

Yamilet Solano

\begin{abstract}
An analysis of the forms that may function as adversative connectives reveals that the most frequent one in Costa Rican educated speech is pero. It cannot be asserted beforehand that a given form serves an adversative function in the different structures in which it appears, for that function depends on both the linguistic and the extralinguistic context.
\end{abstract}

En este artículo pretendo hacer una revisión de las formas nexuales adversativas de una manera descriptiva para determinar cuáles formas tienen este valor y en qué estructuras aparecen en nuestra habla ${ }^{1}$. Es necesario aclarar que tomo las formas mencionadas como adversativas en las gramáticas españolas y luego hago el análisis correspondiente para establecer si su valor es adversativo o no.

En las gramáticas no he encontrado referencias aclaradoras con respecto a este tipo de nexos ${ }^{2}$. Lo único que queda claro al revisarlas es que no hay unidad de criterio en cuanto al tratamiento, función y valores de estas formas. No hay un inventario de conjunciones y frases conjuntivas que nos permita trabajar con mayor seguridad sobre el tema. Unos incluyen algunas formas que otros excluyen con argumentos no muy convincentes. Por ejemplo, algunos consideran sólo las conjunciones "pero" y "sino", mientras que otros incluyen frases adverbiales como "aparte de", "mientras que", "sólo que", y otras por el estilo.

En términos generales el nexo adversativo establece una relación de coordinación entre los dos componentes de la cláusula, uno de los cuales niega o restringe de alguna manera lo que se afirma en el otro ${ }^{3}$. La oposición puede ser restrictiva o exclusiva dependiendo de que la relación existente implique contrariedad o limitación o una total incompatibilidad.
En mis materiales del habla culta costarricense encontré 1167 formas adversativas. Todas pueden tener ese valor dependiendo del contexto. Con esto enfatizo el hecho de que el valor adversativo lo adquiere el nexo por su significado y no por la forma. Veamos como aparecen los nexos adversativos y los valores que adoptan en los distintos contextos.

\section{1. "PERO": 813 apariciones}

Este nexo constituye el $69.7 \%$ del total de formas nexuales que funcionan como adversativas en mis materiales. Queda demostrado que ésta es la forma característica del nexo adversativo en el habla culta costarricense, aunque no en todas sus apariciones tenga valor adversativo.

Este tipo de nexo rompe o desvía la secuencia lógica anterior, opone dos oraciones o marca un relieve expresivo en la oración que introduce el nexo. El contraste que generalmente establece el nexo entre las oraciones que conecta hace que en lingüística de texto se le conozca como "conectivos contrastivos"4.

Este nexo antecede siempre al elemento que coordina. No puede ocupar otras posiciones. Incluso cuando es inicial aparece, como es lógi$\mathrm{co}$, introduciendo la cláusula. Solamente aparece en posición final en discurso fragmentario. 


\section{1. "PERO" en discurso fragmentario: 91 casos}

Ocurre con frecuencia que los hablantes, en su interacción cara a cara, usan mucho el "pero" para concluir un enunciado, y con el gesto y la entonación lo completan. Al transcribir la conversación el texto queda incompleto, fragmentario. Nos ayudamos de los puntos suspensivos para expresar la duda en lengua escrita. Pero el significado específico del enunciado a veces no aparece ni siquiera revisando toda la transcripción ni la grabación, porque hay mucha información elidida. En estos casos no hay ningún elemento de oposiciones para afirmar que tiene valor nexual:

- Hay que dibujar con una precisión pero...

En este caso generalmente el hablante recurre a mecanismos paralingüísticos: el gesto de la mano y la cara hacen que este "pero" se cargue de una connotación especial con un máximo de oralidad con el significado de "demasiado". Se hace un gesto con la mano: se juntan los dedos índice y pulgar con un movimiento hacia adelante que indica exactitud. El gesto de la cara a veces incluye cerrar un ojo en el preciso momento en que se hace el gesto con la mano:

- La fiesta estuvo pero... (estupenda, demasiado bien)

- La comida fue pero... (demasiado rica, más que deliciosa)

También ocurre que a veces el hablante simplemente usa "pero" para concluir porque no tiene todavía organizada la idea que va a expresar, o el interlocutor le interrumpe el turno y entonces deja el enunciado inconcluso. No encontré ni mencionado ni registrado ningún caso de éstos en la bibliografía consultada.

El chiquito tiene derecho a hablar y a decir lo que piensa, lo que siente. Pero... pero...

Y entonces aunque la pensión no es una gran cosa pero...

-Nunca he visto uno en detalle pero... pero si sé...

Pero... pero soy muy desconfiada y...

En estos casos conté el primer nexo pero le di valor funcional y semántico sólo al segundo porque el primero es expresión de duda o inseguridad al planificar el discurso sobre la marcha de la conversación.

\section{2. "PERO" en posición inicial de cláusu- la: 399 apariciones}

Es frecuente su uso como enlace extraoracional al principio de cláusula. Esto ya lo señaló Gili Gaya cuando habla precisamente de "enlaces extraoracionales"s. En estos casos carece de su valor adversativo normal ya que no se refiere a una oración o cláusula anterior sino al sentido general de lo que se ha venido diciendo. Incluso hay 27 casos en que el hablante inicia su turno con un "pero". La Academia nos dice que el "pero" usado en principio de cláusula es extraoracional y que denota alguna restricción a lo dicho anteriormente $^{6}$. En estos casos el nexo toma distintos valores desde el propiamente adversativo hasta el ilativo, como veremos luego. Su frecuencia es la más alta en la muestra. Es un conector que sirve para mantener el discurso, para continuarlo.

Entonces, desde el punto de vista, digamos, cada vez o tratar de obligarme a hacer algo yo diría que me están faltando al respeto a mi persona. Pero hay otras cuestiones que yo diría que son falta de respeto pero hacia lo que nosotros entendemos como el comportamiento que debe tener la mayoría de la gente dentro de un medio.

-Bueno sí me ha tocado ver en varios accidentes. Participar como en dos o tres. Pero los que me han llamado más la atención han sido no personales, sino de tercera persona.

-A mi me gusta más como la Antropología. Pero yo no sé hasta qué punto suponer que los valores éticos han decaido.

-Eduardo fue Secretario de la Facultad de Ciencias y Letras. Pero en la Oficina de Registro fue hasta... llegó hasta Director de la Oficina de Registro.

También ocupa esta posición y ha perdido su valor adversativo cuando introduce interrogaciones o admiraciones. En estos casos el "pero" tiene un valor enfático. Encontramos 11 ejemplos de este tipo:

-Diay, sí, ¿pero entonces qué hago?

$\mathrm{Y}$ te dicen cinco veces seguidas y ya la sexta vez le decis: ¿pero no tiene ojos?

Entonces me decía el doctor: ¿Pero cómo es posible?

Hasta eso, hasta con la vida universitaria porque un amigo que yo tenía estaba en la Universidad estudiando Ingeniería Química y... ¿Perove? 
-¡Pero cómo no lo tuve más claro!

-Pero, iqué sé yo!

-¡Pero ve! A mí no se me ocurrió.

\section{3. "PERO" en estructuras no equivalentes: 121 casos}

La forma "pero" puede aparecer relacionando elementos no equivalentes. En algunos casos hay un matiz restrictivo que hace que el conector siga teniendo valor adversativo. Generalmente lo que ocurre es una elisión de verbo repetido, o en general por elisión de redundancia. Cuando esto ocurre es fácil reconstruir la estructura profunda: "Mi mamá nació aquí en San José pero mi papá en Alajuela". Estoy de acuerdo con Ana María Barrenechea en el tratamiento que hace de estas estructuras, porque precisamente estudia los procesos de elisión en las coordinadas, aunque sigue considerándolas equivalentes porque se perciben los elementos elididos?. Aunque es interesante y válido este enforque, sólo percibo estructuras no equivalentes, a veces complejas, en la estructura superficial:

El Diseño es bellísimo y uno se identifica montones pero basta abi, verdad.

O sea, tiene una idea pero ambigua, una idea general.

-Todo rústico pero con formas bonitas, diferentes a otr... a las de otros parques.

Nos pasamos de casa como a los cuatro kilómetros... un poquito más para arriba, pero nada más.

Sobre todo por esa cuestión de que todavía las chiquitas las mantienen -digamos- ya no tan encerradas en la casa, pero alrededor.

En el habla cotidiana, "pero" es muy expresivo y muy usado para enfatizar el calificativo, también en estructuras no equivalentes. En estos casos vemos que relaciona una oración generalmente con un sintagma nominal: "Hay una adaptación pero tremenda en muy corto tiempo". En un estudio del habla popular es posible que la aparición de este uso de "pero" resulte más significativo, aunque también es frecuente en el habla culta. Encontré 17 ejemplos. En estos casos no hay ninguna relación de la forma "pero" con valores adversativos:
¡Es que va a ser pero fatal!

Y ya había soportado el invierno pero de humedad pero duro duro, una humedad terrible.

Yo aprendi pero barbaridades, barbaridades (muchísimo)

Observemos otros casos de "pero" como elemento enfatizador:

-Ahora, si usted es bueno, usted va a una galería y usted se ubica rapidito. Pero hay que ser bueno.

-En cerámica, escultura y pintura. Pero sí, la gente sí se especializa.

Lo mismo ocurre con la réplica introducida por "pero" en la cual se pone en duda su valor adversativo en el sentido de oponer dos términos, oraciones o cláusulas ya que el contraste se da con respecto a la posición del interlocutor, 33 casos en total:

Inf. - Yo soy católico, Yo soy católico y todo...

Renovación Carismática. De la Renovación Espiritual Católica.

Enc. -¿Y qué es esa cosa?

Inf. - ¿No sabés?

Enc. - No.

Inf. -Es una larga historia.

Enc. -Yo sé que hay mucha secta ahora.

Inf. -No. Pero no es una secta. Vas a perdonar. No.

Enc. -¿La Universidad allá llenó tus espectativas?

Inf. -Sí sí sí. Para lo que yo quería hacer. Es decir, lo logré hacer. Yo estuve allá tres años, que para sacar una Maestría es poco tiempo.

Enc. -Es que no llevabas licenciatura de aquí.

Inf. -No. Pero a mí lo que me interesaba no era tanto el título como la formación.

Enc. -No, porque ellos esperan recibir gente en su consultorio.

Inf. - No. Pero cuál consultorio si los consultorios los tienen los buenos médicos.

\section{4. "PERO" en posición interoracional: 202 casos}

En posición interoracional se presentan dos o más oraciones conectadas en las que la primera expresa la condición suficiente para la negación, la restricción, contraste o énfasis:

-Yo no sé si el papá habrá muerto pero coincidió con la enfermedad. 
-Es técnico y debiera estar en Arquitectura pero está en Bellas Artes.

- Ya pasaron las fiestas de Palmares pero los cien años son este año.

-Yo pienso que la Filosofía es necesaria para todo pero no es suficiente para nada.

-Entonces él cambia su futuro pero no cambia los hechos de ese futuro.

-Diay no, ellos hacen el jueguito pero después no saben ni cómo aplicarlo ni para qué.

En todos estos casos el nexo es interoracional y la relación se establece entre oraciones negativas con afirmativas y si no hay marca de negación el contraste se da por el significado.

\subsection{Uso de "PERO" con refuerzo adverbial: 264 casos}

"Pero" aparece reforzado por formas adverbiales en 264 casos de los 813 (32,5\%). Estas formas pueden enfatizar o debilitar su valor adversativo.

Pero sí y pero no: esta construcción pareciera que refuerza el valor advėrsativo del nexo aunque no necesariamente. Hay casos en que tiene valor continuativo:

-Sí, era un... un... una situación muy fea porque él estaba perdiendo demasiada sangre. Por cierto se salvó. Pero sí, esos dos accidentes los recuerdo muy claro.

Generalmente en las correlaciones "sí... pero no" (2 casos), "no... pero sí" $(9$ casos) el valor adversativo es evidente. Que esta correlación sea restrictiva o exclusiva depende fundamentalmente del contexto.

Sí, se supone, pero no creo.

Si, pero no nos conocimos.

No, nunca me sentí realmente acomplejado porque ellos se sintieran incómodos o me rebatían algún punto que al final de cuentas con la práctica, la experiencia que yo tenía... Pero síme parecía interesante algunos planteamientos teóricos que ellos me hacían.

Si hay diferencias de clase pero no tan profundas como se dan en otras regiones del mismo imperio español.

Bueno, un poquito después de Carlos Luis, pero no tanto después.
Indudablemente se trata de adversativas pero no exclusivas sino restrictivas. Encontramos 31 apariciones de "pero sí" y 66 de "pero no":

existia, por ejemplo, la separación entre los esposos pero no el divorcio.

puede que influya, verdad, pero no necesariamente.

La Filosofia es necesaria para todo pero no es suficiente para nada.

Pero si se han ido muchos.

Pero sí, siempre sueño.

Pero si era importante el hecho de ser asistente ya como tal de la cátedra, verdad.

En mis materiales encuentro casos en que la oposición es enfática, el uso de "pero" tiene como función reforzar la cláusula anterior, no de negarla: "sí... pero sí" o "no... pero no":

Si, pero si se nota.

No no no no. Pero no. Por lo demás no.

Las formas "no... pero..." aparece 85 veces y 18 "sí... pero...".

"Pero" reforzado con "sin embargo" (5 casos) mantiene o refuerza su valor adversativo, generalmente restrictivo, a veces demasiado amplio:

Exactamente. Pero sin embargo creo que... que eso no llena tanto.

Que no pueden pagar la leche a esos precios pero sin embargo no dicen nada.

Ellos no se preocupan por construir. Pero sin embargo tienen una unidad experimental aquí en Caldera.

Enc. - ¿No cabía más en... Investigación eso?

Inf. -Posiblemente, pero tampoco en investigación me lo hubieran aceptado.

El valor adversativo se debilita, se diluye o el "pero" toma otro valor cuando aparece con otras formas adverbiales, como por ejemplo "pero en fin" (1 vez), "pero también" (13 veces), "pero entonces" (10 veces), "pero es que" (14 veces), que le dan a la cláusula un valor continuativo (ilativo, aditivo o causativo). No se adversa sino que se agrega información: 
tiene una... un sistema político totalmente diferente al nuestro. Pero también tenemos crisis politica interna que viene a ser dada por la crisis en... en los partidos.

artificial en el sentido de que uno trajo las especies pero también al distribuirlas ahí en el bosque se trató de hacerlo lo más... dándole a las especies una distribución lo más natural posible.

He participado en accidentes automovilísticos, verdad. Sin consecuencias graves dichosamente pero... pero también he tenido que participar en accidentes eh... donde por... por -digamos- por pleitos no ha muerto una persona.

-Sí. Bajo la protección del Estado. Pero entonces los conquistadores tiene que venir a ver qué encuentran para recuperar las inversiones.

Esa plata no apareció nunca. Pero entonces durante mucho tiempo se trabajó con la promesa de que ya se iba a girar eso.

-Es un solo Castellano Correctivo. Sólo un semestre. Pero entonces dice Cecilia que le cuesta mucho conseguir profesor.

Pero es que es tan entrabado el proceso para no equivocarse en una receta.

Bueno pero es que ella no puede entender esas cosas.

Bueno, pero es que usted sabe que...

Estoy haciendo una tautología. Estoy dando en la definición lo que supuestamente está por ser definido. Pero en fin, es tener una alta valoración de uno mismo (...)

En sintesis, "pero" aparece sin valor adversativo en 190 casos de 813 (23.4\%). Estos serían: 91 en discurso fragmentario, 33 en réplica, 11 interrogaciones y exclamaciones, 17 enfáticos, y 38 continuativos (causativos, consecutivos e ilativos, sin incluir los que puedan interpretarse como tales en posición inicial). En todo caso tampoco incluí las 399 veces que aparece en posición inicial de cláusula, en cuyo caso algunos gramáticos y lingüistas le niegan el valor adversativo por el hecho de que adopta un valor demasiado amplio, interdiscursivo, ya que puede referirse a toda la conversación y no necesariamente a una oración anterior. No incluyo estos casos porque de alguna manera se percibe un matiz adversativo en esta posición. Hay una restricción, aunque leve, de la secuencia discursiva anterior, no importa la extensión del texto al cual se refiere.

No aparecen registradas en mis materiales formas como: "pero por otro lado", "pero de todos modos", "pero de todas formas", "pero de todas maneras", "pero en general", "pero fuera de eso","pero sobre todo", "pero aparte", "pero lógicamente", "pero desde luego". Tampoco encontré formas como "pero en cambio", "pero por el contrario", "pero aparte", que generalmente refuerzan el valor adversativo. Estas formas sí se oyen con alguna frecuencia en el habla culta, pero no aparecieron en la muestra.

\section{2. "SINO": 101 casos}

Por la frecuencia de aparición este es el nexo adversativo más importante después de "pero". Aparece precedido por formas adverbiales negativas: "no (sólo) (solamente)... sino (que)", "nunca... sino (que)", "tampoco... sino (que)", "no... sino más bien", "no... sino también", "no... sino más que todo", etc. Se puede observar que aparece en las estructuras más diversas.

\section{1. "NO (SOLO) (SOLAMENTE)... SINO (QUE)": 74 veces}

Es la forma más frecuente. No hay diferencias notables en cuanto que sea "no sólo" o "no solamente" pero sí hay diferencia de estructura gramatical en cuanto que aparezca "sino" o "sino que". Generalmente cuando aparece "sino" encontramos una frase nominal por un proceso de elipsis del verbo, por reducción de redundancia. Incluí estas cláusulas como conexión de oración con un sintagma nominal:

No lo considera arte sino artesanía, posiblemente.

No vamos a estar peor que antes sino mejor.

Pero este no era un trabajo fijo sino uno de los ocasionales, muy simpático.

no gripes de tres días sino gripes de tres semanas.

no son fuentes primarias directas sino fuentes primarias impresas.

no el arquitecto quinientos cincuenta sino el civil, los electromecánicos y los arquitectos.

no solamente en ese momento, como lo decís, sino desde la época colonial.

No solamente estoy trabajando con los funcionarios sino con familias. 
En cambio cuando aparece "sino que" lo que sigue es una oración, es decir, siempre aparece un verbo conjugado:

En Costa Rica no se hace política sino que es politiquería. O sea, son cosas que uno realmente no sueña sino que las ha pensado.

De pronto ya no había Liceo de Heredia sino que había Escuela Normal.

Registré una excepción en que no hay verbo conjugado y curiosamente es una forma que me parece familiar. Creo que es más frecuente de lo que aparece en la muestra:

Al final nunca fui asistente de la niña Gilda sino que de la cátedra.

En este caso hay elipsis del verbo y la oración sería: "Al final nunca fui asistente de la niña Gilda sino que fui asistente de la cátedra" pero hay mucha redundancia. Lo común es: "Al final nunca fui asistente de la niña Gilda sino de la cátedra". Es el único caso que encontré.

Como dato curioso y que sirve para establecer el contraste entre estas dos estructuras gramaticales tenemos este ejemplo:

"De pronto ya no había Liceo de Heredia sino que había Escuela Normal".

Y aparece otra oración, en boca del mismo informante, con la misma idea pero con la otra forma, "sino", sin verbo conjugado después en la segunda oración:

"¿Qué era esa cosa que ya no había Liceo de Heredia sino Escuela Normal?".

Hay 40 formas "no... sino", 25 "no... sino que", 5 "no solamente... sino que" y 4 "no sólo... sino que": 74 casos.

\section{2. "NO... NI... SINO QUE...":}

Pero también registré otras estructuras oracionales interesantes. Por ejemplo hay varios casos en que la primera oración no tiene sólo un componente negado sino que hay dos o más negaciones antes del nexo "sino":

no el cantón ni el país en que uno vive sino que el mundo tiene una... no con palmetones ni con apretones de manos sino que hay que decirlo seriamente.

no han sido ni económicas ni de trabajo sino más que todo de cuestionarme a mi misma.

La negación no necesariamente tiene que ser el adverbio "no" sino que pueden aparecer otros adverbios negativos:

Al final nunca fui asistente de la niña Gilda sino que de la Cátedra.

Entonces el muchacho nunca tiene un libro completo sino que tiene fotocopias.

Nunca nos habló de usted ni de vos sino de tú a los alumnos.

En este sentido tampoco significa aceptar todo sino a través del diálogo.

La adversación se hace exclusiva al aparecer la negación reforzada por "pero":

pero no es que no sueña sino que no recuerda.

pero no porque se realice el sueño sino porque es parte de la vida de uno.

En este último caso el nexo "sino" conecta dos oraciones causales: "pero no porque... sino porque".

Hay un caso en que "no" y "sino" aparecen contiguos:

Pero desde el punto de vista económico no sino desde el punto de vista del regreso, de la familia.

\section{3. "NO... SINO MAS BIEN...": 5 casos}

no es necesario de que el individuo piense sino más bien lo contrario, entre menos reflexivo mejor, verdad.

Estoy contratado como biólogo. Aún más, no como biólogo sino más bien como zóologo.

\section{4. "NO...SINO TAMBIEN...":}

"Sino" pierde su valor adversativo en la estructura "no... sino también" (5 casos) y "no... sino que también" (2 casos), donde no restringe sino más bien amplía. Tiene valor aditivo:

Porque no se trata solamente de ser como es sino también de ser como las personas quieren que no sea. 
No solamente problemas científicos sino también todos aquellos problemas de infraestructura necesarios para llegar a hacer una investigación seria.

Creer que no sólo yo tengo la razón sino que también los demás tienen razón... verdad.

en un proyecto de éstos no sólo se necesita gente especialista en suelos, sino que también en... en el campo forestal, en gramíneas, en... bueno en todos los campos, verdad: Zoología, Entomología.

\section{3. "Y" seguida de negación: 50 casos}

\section{1. "Y NO": 42 casos con valor adversativo}

La función de la conjunción "y" es generalmente copulativa. Pero si una de las oraciones es afirmativa y la otra negativa este valor copulativo se altera y toma un valor adversativo ${ }^{8}$. En estos casos es sustituible por "pero" ("Quedó de llegar a las doce y nunca llegó", equivale a "Quedo de llegar a las doce pero nunca llegó"). Por supuesto que no todas las coordinaciones que presentan una negación en uno de sus componentes son adversativas. En mis materiales hay un total de 88 apariciones de la conjunción "y" seguida de negación ("y no" aparece 80 veces, "y nunca" $=7$, "y tampoco" =1). De las 80 apariciones de "y no" solamente 42 tienen valor adversativo y aceptan la conmutación por "pero":

este arbolito es el más abundante. $Y$ no sólo es el más abundante sino que ya haciendo los estudios...

puse todos mis datos y mis aspiraciones y todo y no me llamaron.

yo nací en San José y no recuerdo exactamente cómo se llama el Distrito.

Mis dos opciones principales fueron: Veterinaria o Arquitectura. $Y$ no existía en ese tiempo ninguna de las dos.

No es posible sustituir la "y" por "pero" si en la misma cláusula hay otro "pero" porque este último nexo no es recursivo:

llegaba a la una o dos de la mañana a la casa y no me hacían crisis pero no tenía novio.

- llegaba a la una o dos de la mañana a la casa pero no me hacían crisis pero no tenía novio.

Tampoco es posible la conmutación cuando en la primera parte de la oración, anterior al nexo hay una negación:
No tenía posibilidades económicas y no me fui.

- No tenía posibilidades economicas pero no me fui.

Son muy claros todos los casos en que el valor de "y no" no es adversativo.

\section{2. "Y NUNCA": 7 casos con valor adver- sativo}

Claro, yo en el colegio hubiera pensado en Artes Plásticas yo pienso en Profesorado y nunca podría ser profesora.

Y en Guadalupe vivíamos más o menos como a quinientos metros de distancia y nunca nos vimos.

\section{3 "Y TAMPOCO": 1 vez con valor adversativo}

$\mathrm{Y}$ doy quinto $y$ tampoco saben nada.

\section{4. "SIN EMBARGO": 36 apariciones}

Generalmente esta forma aparece como enlace extraoracional con referencia a lo que se ha dicho anteriormente, ya el mismo hablante, ya el interlocutor en el diálogo. Su valor siempre es restrictivo amplio:

Me puedo meter a un colegio a dar clases. Sin embargo no tengo materias de docencia.

Pero mi... mi primera carrera fue Biología y sin embargo me licencié primero en Educación.

nosotros tenemos como cinco o seis especies y sin embargo son totalmente subutilizadas, verdad.

Esta forma tiene cierta autonomía sintáctica y puede aparecer antes o después del verbo o en posición final de cláusula. Aunque generalmente introduce la oración que coordina (30 casos). Recogí dos ejemplos en conversaciones no grabadas: "Saqué notas bajas y gané el curso, sin embargo". "Estaban muy cansados y llegaron caminando hasta la cima, sin embargo". Esta forma se oye en la conversación cotidiana, pero solamente aparece un ejemplo en mis materiales:

¿Cómo voy a salir de aquí? Y salí, sin embargo.

Las únicas conjunciones que refuerzan a esta forma adversativa son "y" y "pero" en la muestra de que dispongo. Aparece 3 veces "y sin embargo" y 5 veces "pero sin embargo". 


\section{5. "CLARO QUE": 34 casos}

Al igual que "más bien", esta locución adverbial funciona como conjunción correctiva conmutable por "pero". Esto hace que en muchos contextos tome un valor adversativo:

- Claro que las muñecas ya no son las de antes, verdad.

Claro que al final no tenía ningún porcentaje en la evaluación pero era obligatorio.

- Claro que eso también se debe a la televisión.

- Claro que es más barato, definitivamente.

\section{6. "AHORA": 31 casos como conector}

Esta forma aparece 239 veces en total. En esas apariciones hay 208 con valor de adverbio de tiempo, $87 \%$, y 31 en función nexual, 13\%.

El historiador es un cientista social. Abora, eso es más una pretención que una realidad.

Esta forma es equivalente a:

El historiador es un cientista social. Pero eso es más una pretención que una realidad.

Los casos en que este valor aparece se diferencian claramente de aquellos en que no son nexuales porque son adverbios de tiempo.

Cuando actúa cono nexo el "ahora" presenta dos particularidades, a mi manera de ver, que son casi obvias: primero, aparece introduciendo a la oración que coordina, y segundo que generalmente marca una pausa antes de que aparezca el segundo componente de la coordinación. Es más difícil de especificar su valor cuando aparece como elemento iniciador de cláusula porque puede ser adverbio de tiempo, puede ser nexo adversativo o nexo marcador de transición temático-discursiva.

\section{7. "MAS BIEN": 36 veces en cláusulas adversativas}

Es importante hacer notar que en diez ejemplos aparece como refuerzo adverbial de "sino" y "pero". Sin embargo también aparece 26 veces como forma nexual restrictiva:
Actualmente se trata más bien de deshacer lo graduado de las escuelas.

Y después la paloma se compone, e... es más bien el hombre, verdad, que la paloma.

Inf. -Bueno, en este momento, cuando yo empecé el trabajo ahí había un bosque... eh.. un sendero. Pero fue hecho así, digamos...

Enc. - ¿Un trillo?

Inf. -...de cemento. No, no. Más bien de concreto, muchacha, carísimo.

\section{8. "EN CAMBIO": 12 casos}

Esta forma tiene un valor restrictivo que apenas se percibe. En realidad lo encuentro ambiguo. Por un lado es como una oposición comparativa y por otro como explicativa. Sin embargo, tiene el mismo valor de "pero" y es conmutable. Creo que, como lo que establece las diferencias es el significado y no la forma, es difícil a veces señalar límites precisos.

Uno jugaba por amor a la camiseta. Y en cambio ahora se juega por amor a la plata.

Se puede observar que hay dos elementos que se comparan con un elemento común: "jugar por amor", entre antes-ahora y camisetaplata. Hay que recordar que la adversativa generalmente opone dos elementos: A pero B. En ese sentido no hay problema en considerar este nexo como adversativo. Lo vemos claramente si en la misma coordinación anterior sustituimos "en cambio" por "pero":

Uno jugaba por amor a la camiseta. Pero ahora se juega por amor a la plata.

En los doce ejemplos en que aparece esta forma tiene un valor restrictivo. Siempre aparecen dos o más elementos relacionados por el nexo. Aunque aparezca en posición inicial de cláusula su valor depende de la cláusula anterior, es decir, nunca aparece en posición inicial absoluta como ocurre con el valor enfático de "pero".

Yo la tarea la hacía porque era mi responsabilidad y punto, verdad. En cambio ahora los chiquitos con mucha frecuencia son ayudados por los padres, verdad.

Vemos que los elementos que se oponen son: responsabilidad-ayuda (responsabilidad- no responsabilidad), yo-los chiquitos, antes-ahora. 
el civil es más... de una labor más definida. En cambio el arquitecto es más inquieto, más coordinador.

de otras tenés bibliografía ahí que no termina uno de consultarla. En cambio con estas especies es una fuente grande para el investigador.

Un biólogo habla de la chucheca, la almeja y el mejillón y establece una comparación pero con matices de adversativa:

En cambio el mejillón, siendo más rico, más proteínico, es menos apreciado.

El Talgo vale seis mil pesetas. Casi, casi, las seis mil pesetas. En cambio el otro vale tres mil trescientas pesetas.

En los doce casos que encontré en la muestra se establece este tipo de correlación que me hace pensar en una restricción apenas perceptible, puesto que el nexo puede ser sustituido por "pero". También podría pensarse en un valor distributivo o simplemente ilativo. En todo caso no pretendo resolver aquí esta ambigüedad puesto que ese no es el propósito de mi estudio. Obsérvense las posibles sustituciones:

El Talgo vale seis mil pesetas. Casi casi las seis mil pesetas. Pero el otro vale tres mil trescientas pesetas.

El Talgo vale seis mil pesetas. Casi casi las seis mil pesetas. Yel otro vale tres mil trescientas pesetas.

Uno jugaba por amor a la camiseta $y$ ahora se juega por amor a la plata.

\section{9. "SOLO QUE": 14 casos}

Esta forma también funciona como nexo restrictivo:

Yo podría haber salido (del país) sin ningún problema. Sólo que entre salir a estudiar Veterinaria y salir a estudiar Arquitectura, preferí estudiar Arquitectura.

no era un bosque natural, era un bosque artificial. Sólo que un señor de muchos años atrás, sesenta años atrás o cincuenta años atrás, se había dedicado a reforestar esa área con especies de la zona.

\section{0. "A PESAR DE": 14 apariciones}

Es innegable el significado restrictivo que le da a la cláusula esta forma nexual: "Superó su enfermedad a pesar de la falta de cuidados".
De manera que, a pesar de que... que éramos sólo varo nes, la mayor parte del personal docente eran maestras.

no puede controlar el miedo que le dan los payasos a pesar de ser ya ahora una adolescente.

Yo creo que esto se puede entender porque Guardia, a pesar de haber asumido la dictadura desde el año $1870, \sin$ embargo era un liberal convencido.

\section{1. "APARTE DE": 5 casos}

Esta forma funciona como nexo adversativo en 5 de las 6 apariciones que hay en la muestra.

O sea, yo con Chile no tengo... aparte de que mis papás son chilenos, yo no tengo nada que ver.

es uno de los críticos número uno de los sistemas vigentes aparte de que es como un inglés, verdad, sus horas, su desayuno, sus almuerzos, su comida.

\section{2. "AUNQUE": 4 casos}

Esta conjunción concesiva presenta muchos problemas por su vaguedad o porque aparece con otros valores, sobre todo adversativos ${ }^{9}$. La Academia ${ }^{10}$ advierte esta falta de límites precisos puesto que puede tener ambos valores. Sin embargo la misma Academia hace la confusión ya que el Diccionario registra este nexo como adversativo restrictivo ${ }^{11}$. El Dr. Lope Blanch trata el asunto y aclara que la concesiva se da cuando implica causalidad de alguna manera porque cuando "aunque" tiene valor adversativo ninguno de los componentes de la coordinación es causa ${ }^{12}$. Pone el siguiente ejemplo: "Aunque es inteligente, no supo resolver el problema". (Concesiva: el ser inteligente es causa de resolver el problema). "Es inteligente pero no supo resolver el problema" = adversativa. Esto equivaldría, a mi juicio, a decir que igualmente sería adversativa "Es inteligente, aunque no pudo resolver el problema". En estos casos es posible conmutar "aunque" por "pero"13. Hice esto en los 26 ejemplos en que aparece "aunque" y solamente en 4 de ellos es posible. En los otros casos es absurda la conmutación:

(Don Omar) fue un verdadero pionero, muy adelante de su época aunque es hijo de la época, como ya lo has explicado, por la generación a la que perteneció 
(Don Omar) fue un verdadero pionero, muy adelante de su época pero es hijo de la época, como ya lo has explicado por la generación a la que perteneció.

En cambio se puede observar que no es posible el cambio cuando la oración marcada por el nexo implica causalidad:

Sí, porque el año pasado, aunque no estaba aprobado el proyecto, nosotros fuimos a las escuelas.

- Sí, porque el año pasado, pero no estaba aprobado el proyecto, nosotros fuimos a las escuelas.

\section{3. "NADA MAS QUE": 4 ejemplos con valor adversativo:}

Y en la casa, claro, nada más que español.

\section{4. "MIENTRAS QUE": 3 casos con valor restrictivo:}

Aquí pagan dedicación exclusiva mientras que allá no.

(los cursos) que yo di, este... como eran anuales, mientras que en la Escuela de Biología eran semestrales.

\section{5. "EXCEPTO": 3 veces}

(no tenian) ningún contacto con el alumno, excepto la hora de clase: (...)

He vivido en San José prácticamente toda la vida y en... excepto por un par de periodos relativamente cortos que he vivido en el exterior.

\section{6. "SALVO": 1 vez}

pero eso de ir cada semana, salwo que sea en avión.

\section{7. "EN VEZ DE": 3 casos}

Aparece como nexo exclusivo en las tres ocasiones y como introductor de oraciones de infinitivo:

indican, pues, una forma de abordar los problemas que en vez de superarlos - pues la persona que irrespetó cumplió con su objetivo (...)

un carro en vez de andar por el lado derecho de la calle estaba andando en media calle.

\section{8. "EN LUGAR DE": 3 veces}

Las tres veces aparece con valor adversativo exclusivo y también introduciendo oraciones de infinitivo:

-Pero sí observé que en lugar de agarrar para San José, agarramos como para Alajuela.

No aparecen en mis materiales algunas formas registradas en el Cuestionario ${ }^{14}$ como: "mas", "empero", "no obstante", "con todo", "ora", "que no" (que aparece en la muestra 158 veces pero introduciendo oraciones subordinadas negativas, ningún caso con valor adversativo), "únicamente que", "solamente que" (obsérvese que "sólo que" aparece 14 veces con este valor) y "a menos que". Algunas de estas formas son corrientes en el habla cotidiana costarricense pero otras, según mi experiencia y mi propia actuación lingüística, no sólo no las encontramos en la muestra sino que no las encontramos en el habla de ningún estrato social en Costa Rica: "mas", "ora" y "empero".

En lo que hemos revisado hemos podido ver que los nexos no pueden analizarse desde el punto de vista de su estructura formal y que deben ser abordados desde sus valores semánticos y pragmáticos. No podemos señalar nexos adversativos específicos sino formas nexuales que funcionan como adversativas en algunos tipos de conexión dependiendo del contexto. Por ejemplo el DRAE señala como conjunciones adversativas "pero" y "sino" 15, pero vimos que no siempre su valor es adversativo. Que lo sean o no depende del contexto.

\section{Notas}

1. Yamilet Solano. (1989). El babla culta costarricense. Materiales para su estudio. México: UNAM. Recolección y selección de datos para su tesis doctoral sobre los nexos en el habla de San José.

2. Sin duda alguna, los trabajos mencionados de Cecilia Rojas Nieto, citados en la bibliografia, sobre todo el de los nexos adversativos y el de los nexos interoracionales, han sido invaluables.

3. Esbozo (1985): "Cuando en la oración compuesta se contraponen una oración afirmativa y una negativa, la coordinación es adversativa, es decir, opone dos juicios de cualidad lógica contraria". p. 510. 
4. Van Dijk, (1980). p. 134.

5. Gili Gaya. (1967). p. 326. Dice el autor que precisamente porque unen la oración con el sentido general de lo que se viene diciendo y que en esta posición toman un valor ilativo o continuativo.

6. Esbozo de la Real Academia de la Lengua Española. (1985). p. 511.

7. Ana María Barrenechea. (1977). p. 499.

8. Gili Gaya. (1964) p. 281 y Cecilia Rojas Nieto. (1977). "Los nuevos nexos adversativos..." Op. cit., pp. 222-223.

9. Gili Gaya (1967) dice que hay casos en que "aunque" se presenta con valores intermedios entre la concesiva y la adversativa. p. 281.

10. Esbozo de la Real Academia (1985) dice que "aunque" tornó de su primitio empleo en la subordinación concesiva el que tiene ahora en la coordinación adversativa. p. 512.

11. DRAE (1970) encontramos "aunque" registrado como conjunción adversativa con que se denota oposición a pesar de la cual puede ser, ocurrir o hacerse alguna cosa. p. 143.

12. Juan M. Lope Blanch. (1983) dice que es adversativa cuando la oración marcada por el nexo no es causa de la oración complementada. Concesiva si el nexo marca una causa de la otra oración. p. 36.

13. Andrés Bello. (1984). pp. 350-351.

14. Comisión de Lingüística Iberoamericana (1971). Cuestionario para el estudio coordinado de la norma lingüística culta de las principales ciudades de Iberoamérica y de la Península Ibérica. Tomo II. Madrid.

15. Diccionario de la Real Academia (1970) p. 1010 y 1206 respectivamente.

\section{Bibliografia}

Alarcos Llorach, Emilio. (1973). Estudios de gramática funcional del español. Madrid: Gredos.

Alcina, Juan y José Ma. Blecua. (1980). Gramática Española. (2a. ed.) Barcelona: Ariel.

Alonso, Amado. (1976). Estudios Lingüísticos. Temas hispanoamericanos. (3a. ed.) Madrid: Gredos.
Alvar, Manuel. (1983). Estructuralismo, geografia lingüística y dialectología. (2a. ed.) Madrid: Gredos.

Arroyo, Victor Manuel. (1971). El babla popular en la literatura costarricense. San José: Publicaciones de la Universidad de Costa Rica.

Bello, Andrés. (1984). Gramática de la lengua castellana. Madrid: EDAF Universitaria.

Bernstein,B. (1974). "Códigos amplios y códigos restringidos: sus orígenes sociales y algunas consecuencias. En: Garvin y Lastra Antología de estudios de etnolingüútica $y$ sociolingüítica. México: UNAM.

Bernárdez, Enrique. (1982). Introducción a la lingüística del texto. Espasa-Calpe.

Beaugrand y Dressler. (1981). Introduction to Texlinguistics. London and New York: Logman.

Carbonero Cano Pedro. (1975). Funcionamiento lingüístico de los elementos de relación. Sevilla: Publicaciones de la Universidad de Sevilla.

Comisión de Lingüística Iberoamericana (PILEI) Cuestionario para el estudio coordinado de la norma lingüística culta de las principales ciudades de Iberoamérica y de la Peninsula Ibérica. Tomo II Morfosintaxis. Madrid: Consejo Superior de Investigaciones Científicas.

Coseriu, Eugenio. Sistema, norma y habla. Madrid: Gredos.

(1982). Sentidos y tareas de la dialectología. México: UNAM. Instituto de Investigaciones Filológicas.

Danjou-Faluax, Nelly. "Propositions pour une définition de au'contraire'. Reflexion sur un oprerateur dántonymie discursive". Modéles Linguistiques, Tomo I, Fasc. 2 Centre Interdisciplinaire de Recherches en Linguistique. Presses Universitaires de Lille. pp. 61-95. 
Firbas. En: (1978). Current Trends in Texlinguistics. Berlín-New York: Walter de Gruyter.

Fuente Rodríguez, Catalina. (1987). Enlaces extraoracionales. Sevilla: Ediciones Alfar.

Gagini, Carlos. (3a. ed, 1975). Diccionario de costarriqueñismos. San José: Editorial Costa Rica.

Gili Gaya, Samuel (1982). Curso superior de sintaxis española. (10a. ed.) Madrid: Aguilar.

Gleitman, Lita R. "Coordinating Conjuntions in English". Language XLI. pp. 260-293.

Gutiérrez Arauz, María de la Luz. (1978). Estructuras sintácticas del español. Madrid.

Guitarte, Guillermo. (1975). Siete estudios sobre el español de América. México: UNAM. Instituto de Investigaciones Filológicas.

Halliday, M.A.D. \& Hasan, R. (1976). Cobesion in English. London, Longman.

Hammarströn, Göram. (1975). Dos estudios dialectológicos. México: UNAM. Instituto de Investigaciones Filológicas.

Herrera, Ma. del Carmen. (1986). "Esbozo de un análisis semántico de pero". Actas del II Congreso Internacional sobre el español de América. México: UNAM. Facultad de Filosofía y Letras. pp. 538-541.

Herrera, Ma. Eugenia. (1984). Los nexos subordinantes adverbiales en el babla popular de la ciudad de México. (Tesis de Maestría) Universidad Nacional Autónoma de México. Facultad de Filosofía y Letras.

Hudson, R. A. (1981). La sociolingüística. Barcelona: Anagrama.

Jara M. Karla V. (1988). "El léxico de origen indígena en la norma culta de San José". Rev. de Filología y Lingüística Vol. XIV (1) pp. 109-124.
Jespersen, Otto. La filosofía de la gramática. 1978. Barcelona: Anagrama.

Lavandera, Beatriz. (1985). Curso de Lingüistica para el análisis del discurso. Buenos Aires: Centro editor de América Latina.

Leñero Elu. Ma. del Carmen. Elementos relacionantes interclausulares en el babla culta de la Ciudad de México. (Tesis) UNAM: Facultad de Filosofía y Letras $\mathrm{s} / \mathrm{f}$.

Levinson, Stephen. (1985). Pragmatics. London: Cambridge University Press.

Lope Blanch, Juan M. (1979). El concepto de oración en la lingüistica española. México: UNAM. Instituto de Investigaciones Filológicas.

Lope Blanch, Juan M. (1986). El estudio del español bablado -culto. Historia de un proyecto. México: UNAM. Instituto de Investigaciones Filológicas, 1986.

(1983). Análisis gramatical del discurso. México: UNAM. Instituto de Investigaciones Filológicas.

(1971). (Coor) El babla de la ciudad de México. Materiales para su estudio. UNAM. Instituto de Investigaciones Filológicas.

(1985). El habla de Diego de Ordaz. Contribución a la bistoria del español americano. México: UNAM. Instituto de Investigaciones Filológicas.

(1986a). Estudios de Lingüística española. México: UNAM. Instituto de Investigaciones Filológicas.

(1983). Estudios sobre el español de México. México: UNAM. Instituto de Investigaciones Filológicas.

(1979). Investigaciones sobre dialectología mexicana. México: UNAM. Instituto de Investigaciones Filológicas. 
(1969).La Filología Hispánica en

México. México: UNAM. Instituto de Investigaciones Filológicas.

. (Editor) (1980). Perspectivas de la Investigación Lingüística en América. Memoria. México: UNAM. Instituto de Investigaciones Filológicas.

(Editor) (1977). Estudios sobre el español bablado en las principales ciudades de América. México: UNAM. Instituto de Investigaciones Filológicas.

López, María Luisa. (1972). Problemas y métodos en el análisis de preposiciones. Madrid: Gredos.

Lozano et al. (1982). Análisis del discurso. Hacia una semiótica de la interacción textual. Madrid: Cátedra.

Lyons, John. (1981). Introducción en la Lingüüstica teórica. 6a. ed. (Trad. de Ramón Cerdá) Barcelona Teide.

Martinet, André. (1978). Estudios de sintaxis funcional. (Trad. Esther Diamante). Madrid: Gredos.

Moreno de Alba, José G. (1979). "Coordinación y subordinación en la gramática española". Anuario de Letras XVII pp. 5-58.

(1985). Valores de las formas verbales en el español de México. México: UNAM. Instituto de Investigaciones Filológicas.

Nebrija, Antonio de. (1984 2a. ed. con estudio introductorio de Antonio Quilis). Gramática de la lengua castellana. Madrid: Editora Nacional.

Obregón Muñoz, Hugo. (1985. Introducción al estudio de los marcadores interaccionales del babla dialogada en el español de Venezuela. Caracas: Centro de Investigaciones Lingüisticas y Literarias Andrés Bello.
Palacios, Margarita. (1986). "Las relaciones interclausurales" Actas del II Congreso Internacional sobre el español de América. México: UNAM. Facultad de Filosofía y Letras pp. 648-653.

(1983). Sintaxis de los relativos en el babla culta de la ciudad de México: UNAM. Instituto de Investigaciones Filológicas.

Puig, Luisa. (1983). "En torno a la conjunción perd". Nueva Antropología. Rev. de Ciencias Sociales. Vol. VI. No. 22 pp. 107-119.

Real Academia Española. (1985). Esbozo de una nueva gramática de la lengua española. 10 a reimpresión. Madrid: EspasaCalpe.

Roca-Pons, J. (1985). Teorias granaticales $y$ análisis sintáctico. Barcelona: Teide.

Rojas Nieto, Cecilia. (1982). Las construcciones sindéticas en el español bablado culto de la ciudad de México. México: UNAM. Instituto de Investigaciones Filológicas.

Seco, Rafael. (1972). Gramática esencial del español. Madrid: Aguilar.

Seco, Rafael. (1982). Manual de gramática española. Madrid: Aguilar.

Stubbs, Michael. (1987). Análisis del discurso. Análisis Sociolingüústico del lenguaje natural. Madrid: Alianza Editorial.

Tusón, Jesús. (1981). Intoducción a la gramática. Barcelona: Teide.

Van Dijk, Teun. (1980). Estructuras y funciones del discurso. México: Siglo XXI. editores.

Cátedra. (1980) Texto y contexto. Madrid: . (1983) La ciencia del texto. Barcelona: Ed. Paidós. 


\section{Anexo}

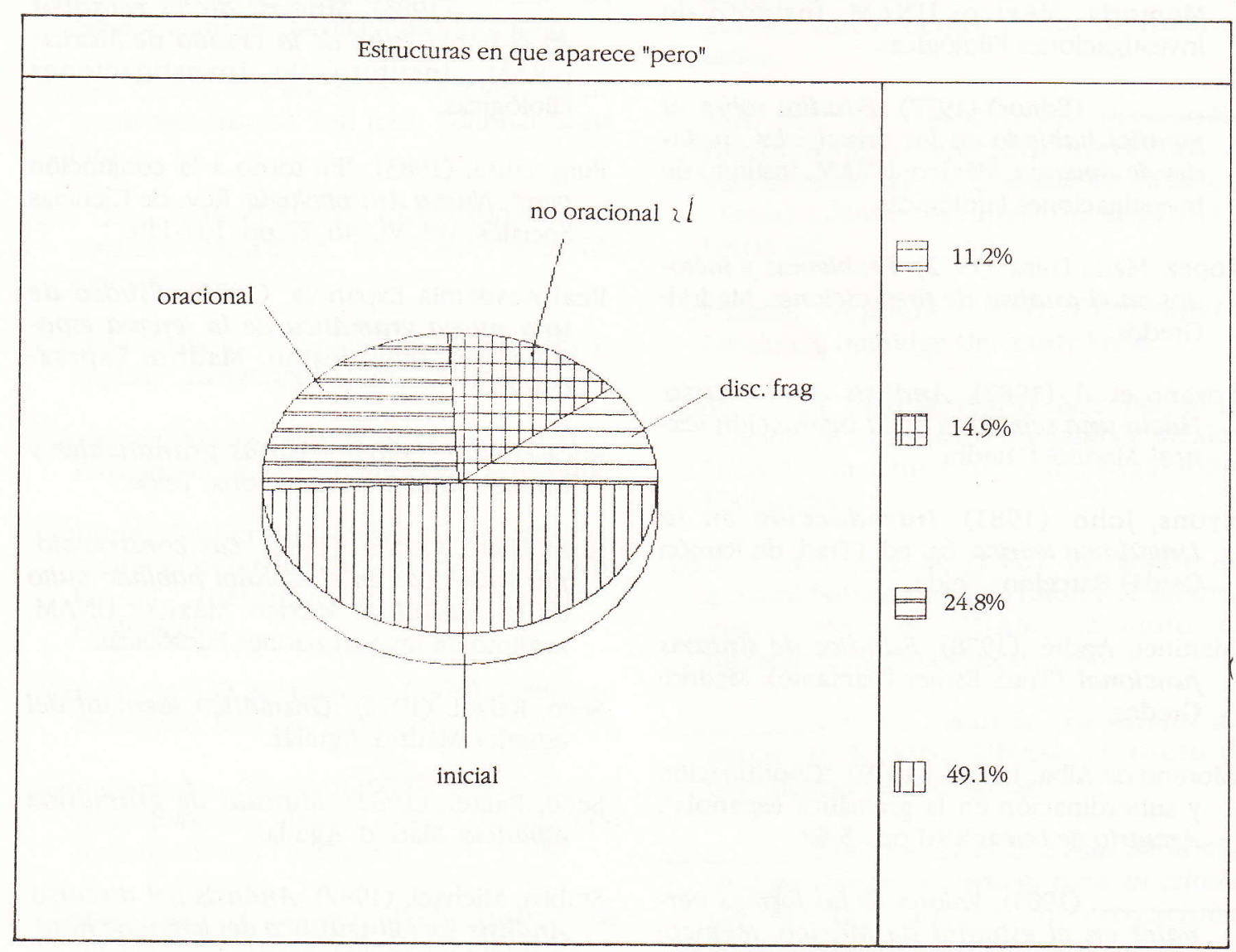


Uso de la forma "pero"

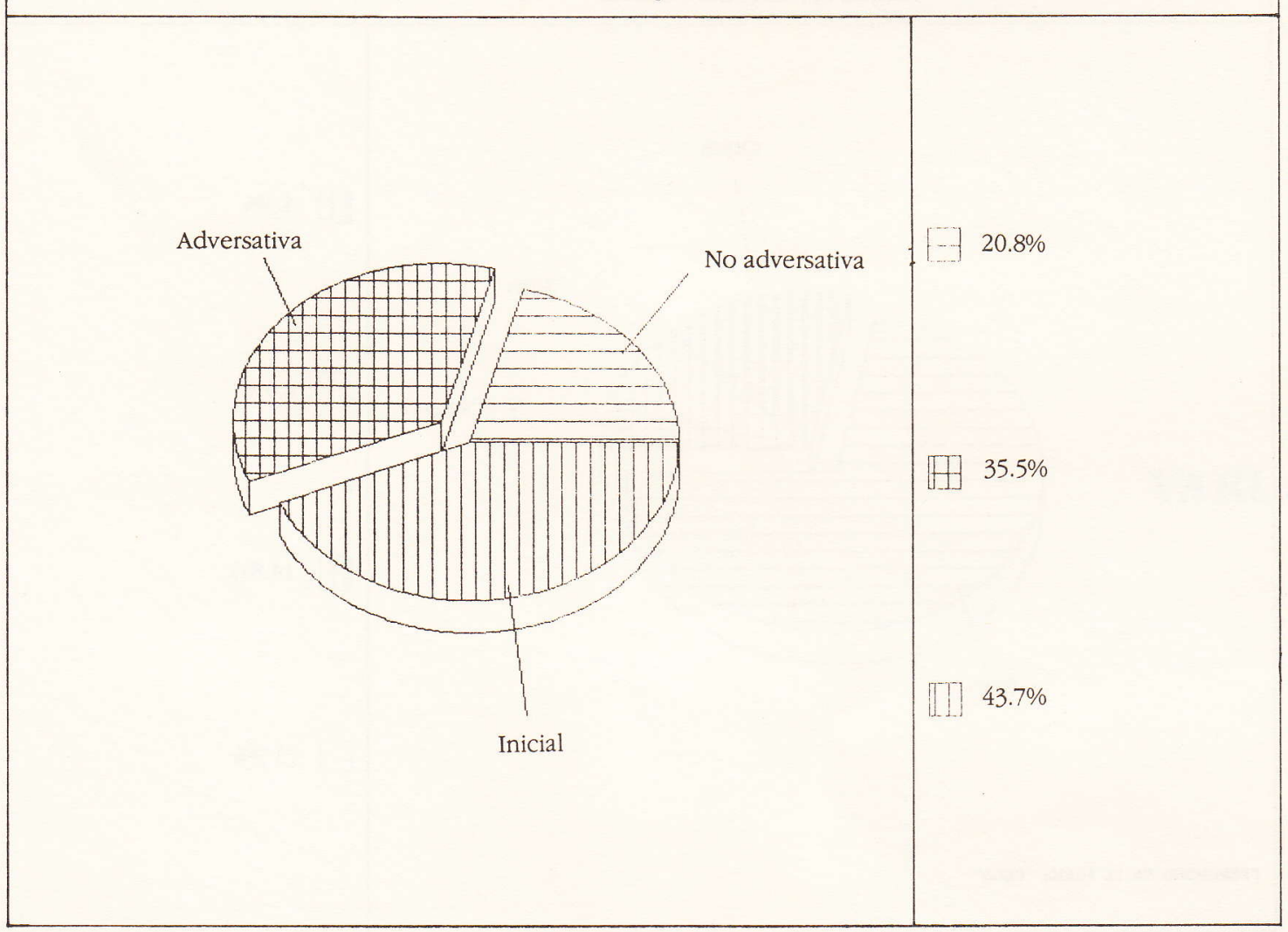




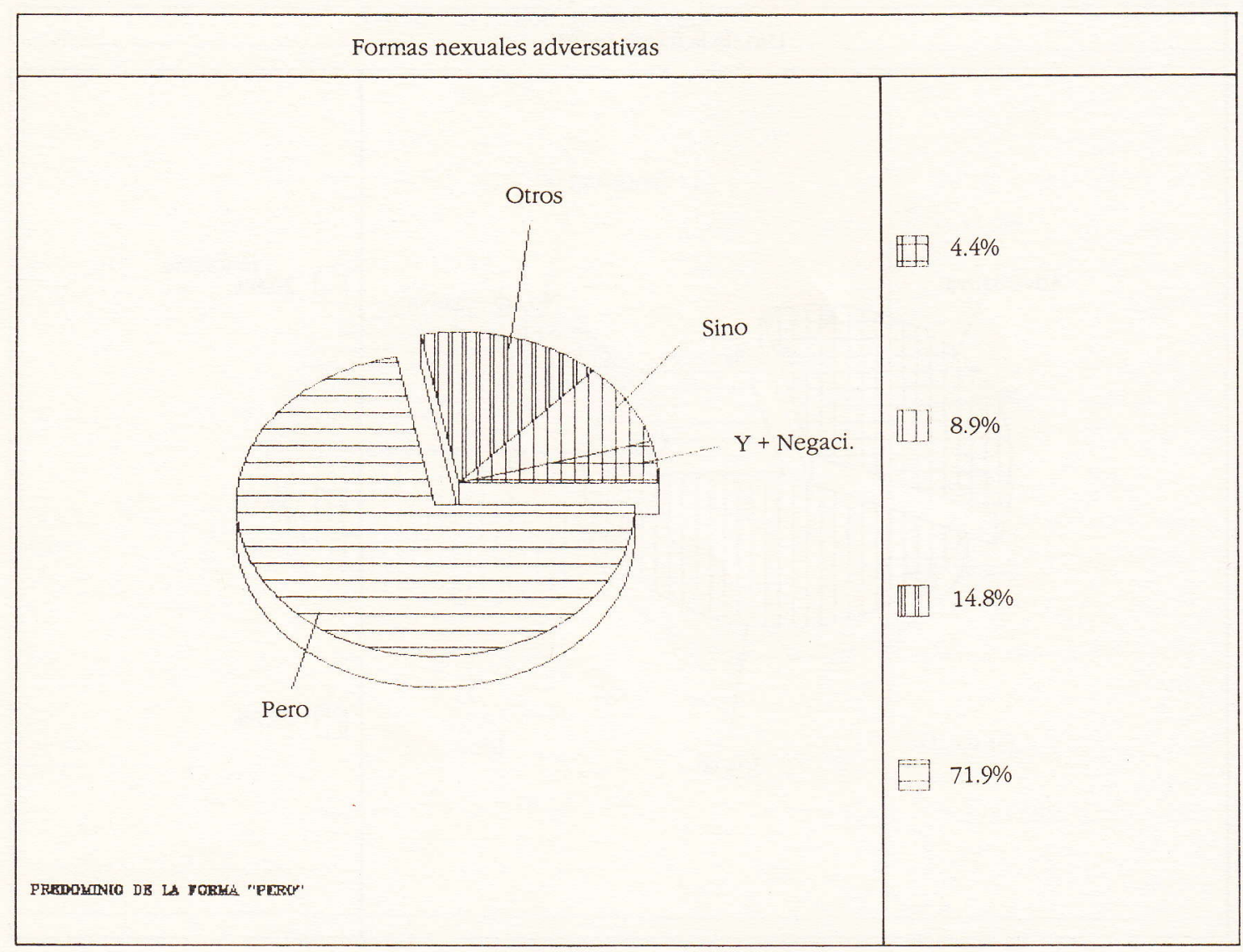

